\title{
Mutation analysis of thyroid peroxidase gene in Chinese patients with total iodide organification defect: identification of five novel mutations
}

\author{
J-Y Wu ${ }^{1,2}$, S-G Shu ${ }^{3}$, C-F Yang ${ }^{1,2}$, C-C Lee ${ }^{1}$ and F-J Tsai ${ }^{1,2}$ \\ ${ }^{1}$ Department of Medical Research, China Medical College Hospital, Taichung, Taiwan \\ ${ }^{2}$ Department of Medical Genetics, China Medical College Hospital, Taichung, Taiwan \\ ${ }^{3}$ Department of Pediatrics, Taichung Veteran General Hospital, Taichung, Taiwan \\ (Requests for offprints should be addressed to F-J Tsai, Department of Medical Genetics, China Medical College Hospital, Taichung, Taiwan 404; \\ Email:d0704@www.cmch.org.tw)
}

\begin{abstract}
Total iodide organification defect (TIOD), where the iodide in the thyroid gland cannot be oxidized and/or bound to the protein, is caused by a defect in the thyroid peroxidase (TPO) gene. Single strand conformation polymorphism analysis was used to screen for mutations in the TPO gene from five unrelated TIOD patients in Taiwan, and five novel mutations were detected. Three of these were frameshift mutations: a single $\mathrm{T}$ insertion between nucleotide position 2268 and 2269 (c.2268-2269 insT) in exon 13 and two single $\mathrm{C}$ deletions at nucleotide positions 843 (c.843 delC) and 2413 (c.2413 delC) in exon 8 and 14 respectively. The other two were single nucleotide substitutions (c.G1477>A and c.G2386> T) located in exons
\end{abstract}

9 and 13 respectively. While the former would result in amino acid substitution (Gly493Ser) in the highly conserved region of the TPO polypeptide, the latter would result in either amino acid substitution (Asp796Tyr) or alternative splicing. Of those identified TPO mutations, c.2268-2269 insT was most prevalent and was detected as heterozygous in all but one TIOD patients. All five TIOD patients investigated in this study were compound heterozygous. The method presented in this study could be used for carrier assessment and mutation analysis of newly identified TIOD patients.

Journal of Endocrinology (2002) 172, 627-635

\section{Introduction}

Congenital hypothyroidism is detected by one of the five tests that are included in the newborn screening program in Taiwan. Its prevalence rate of 1 in 4000 is second only to glucose 6-phosphate dehydrogenase deficiency. Most cases of congenital hypothyroidism result from dysembryogenesis of the thyroid gland. Hereditary inborn errors in thyroid hormone synthesis are found in 10-20\% of these patients and are mostly caused by defects in the synthesis of thyroid hormones (Bikker et al. 1994, Vassart et al. 1995). About half of these inherited thyroid diseases are caused by an iodide organification defect, characterized by the reduced ability to retain iodide in the thyroid gland. In thyroid follicular cells, iodide is actively transported inside through the sodium iodide symporter (Dai et al. 1996, Pohlenz et al. 1998). Covalent binding of the iodide to the tyrosine residues (iodide organification) within the thyroglobulin $(\mathrm{Tg})$ molecule and its subsequent coupling yields the thyroid hormones thyroxine $\left(T_{4}\right)$ and triiodothyronine $\left(\mathrm{T}_{3}\right)$. Thyroid peroxidase, which requires the presence of hydrogen peroxide for enzyme activity, is responsible for the tyrosine iodination and coupling in $\mathrm{Tg}$ (Taurog 1996). Complete absence of thyroid peroxidase activity has been shown in patients with total iodide organification defect (TIOD). Patients with TIOD were demonstrated to discharge more than $90 \%$ of the intrathyroidal iodide pool within half an hour after administration of perchlorate ion (a competitive inhibitor of iodide transport). The human thyroid peroxidase (TPO) gene is located on chromosome $2 \mathrm{p} 25$ (Endo et al. 1995). It consists of 17 exons and spans about 150 kilobases in genomic DNA. Full-length TPO mRNA is about $3 \mathrm{~kb}$ (Kimura et al. 1987, Libert et al. 1987, Magnusson et al. 1987a). TPO mutation was first reported by Abramowicz et al. (1992). Since then, more than ten TPO mutations have been identified (Bikker et al. 1994, 1995, 1997, Kotani et al. 1999, Pannain et al. 1999, Bakker et al. 2000). While most TPO mutations have been well characterized in TIOD patients of various ethnic populations in recent years, none have been reported in Chinese TIOD patients. In this study, we present the molecular studies of five Taiwan Chinese TIOD patients and the identification of five mutations, all of which are novel. 


\section{Subjects and Methods}

\section{Patients and DNA isolation}

Five TIOD patients from five unrelated families were included in this study. All patients were of Chinese descent. Three patients (patients A, C, and D; Table 1) were born before 1984, when there was no neonatal screening for congenital hypothyroidism $(\mathrm{CH})$ in Taiwan. They were diagnosed with $\mathrm{CH}$ on the basis of clinical symptoms at the age of 4-5 months. Since 1984, all newborns in Taiwan are screened for $\mathrm{CH}$ by measuring thyroid stimulating hormone (TSH) concentration in blood from a heel puncture. Elevated TSH was detected in two patients (patients B and E) by the neonatal screening program. Patients with congenital hypothyroidism were etiologically diagnosed as having total iodide organification defect (TIOD) with a positive perchlorate discharge test. The clinicopathological characteristics of these TIOD patients are listed in Table 1 and all five patients have a similar clinical presentation of low plasma $T_{4}$ and $T_{3}$ and high plasma TSH. All parents of the patients gave informed consent. Genomic DNA was prepared from patients diagnosed with TIOD and their relatives following the standard procedures.

Single strand conformation polymorphism (SSCP) analysis and DNA sequencing

Exons 1-17 of TPO gene were PCR amplified and all except exon 8 were subjected to mutation analysis by SSCP using a GenePhor DNA Electrophoresis System (Pharmacia, Uppsala, Sweden). Since exon 8 was too large to be effectively screened by SSCP, it was broken down into two PCR fragments and sequenced directly. The primers used for PCR amplification are listed in Table 2. The PCR products were first diluted with a sample buffer $(10 \mathrm{mM}$ Tris, $1 \mathrm{mM}$ EDTA, xylene cyanol $0.05 \%$, bromophenol blue $0 \cdot 04 \%$, adjusted to $\mathrm{pH} 7 \cdot 5$ with acetic acid) to about $2 \mathrm{ng} / \mu \mathrm{l}$ and then denatured $1: 1$ in a denaturing solution (formamide 94\%, xylene cyanol $0.05 \%$, and bromophenol blue $0.04 \%$ ) at $95{ }^{\circ} \mathrm{C}$ for $5 \mathrm{~min}$ and thereafter were placed directly on ice to prevent reannealing of the single stranded products. Treated samples were then applied to a GeneGel Exel 12.5/24 kit (Pharmacia) following the manufacturer's recommendation. Exons that exhibited irregular shifts by SSCP were subjected to direct sequencing for mutation identification. Before direct sequencing, PCR fragments were purified from agarose gel using QIAEX II (Qiagen, Hilden, Germany). Direct sequencing was performed using a Taq DyeDeoxy Terminator sequencing kit (PE Applied Biosystems, Foster City, CA, USA) with an ABI Prism 377 DNA sequencer (PE Applied Biosystems).

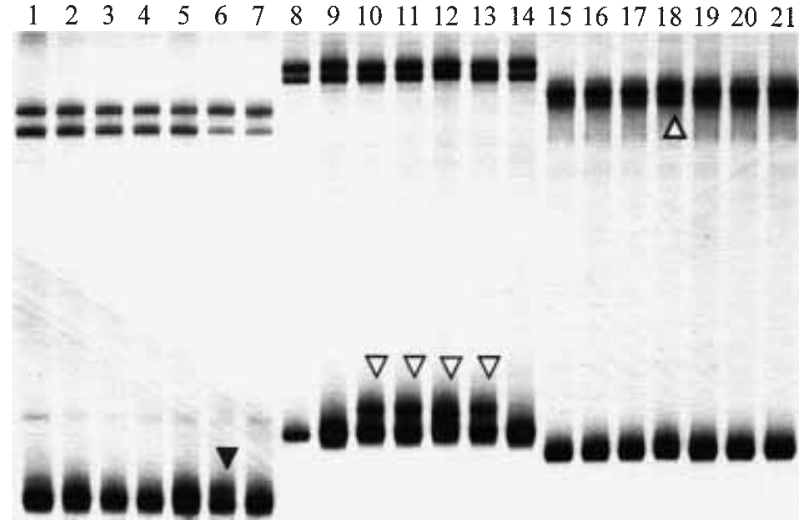

Figure 1 Single strand conformation polymorphism (SSCP) analysis of amplified thyroid peroxidase (TPO) gene exon 9, exon 13 and exon 14 fragments in five total iodide organification defect (TIOD) patients. Lanes 1-7, amplified exon 14 fragments; lanes 8-14, amplified exon 13 fragments; lanes 15-21, amplified exon 9 fragments. Normal controls, lanes 1, 7, 8, 14, 15, and 21; patient A, lanes 2, 9 and 16; patient B, lanes 3, 10 and 17; patient C, lanes 4, 11 and 18; patient D, lanes 5, 12 and 19; patient E, lanes 6, 13 and 20. Solid reverse triangle, open triangle and open reverse triangles indicate where the aberrant shifts are in the gel.

\section{Results}

SSCP analysis of TPO gene

In the five investigated Taiwanese families, all patients presented with TIOD. Exons and exon/intron boundaries of the TPO gene were amplified by polymerase chain reaction and then screened by SSCP. PCR fragments showing aberrant shifts were then directly sequenced to identify any nucleotide changes. Figure 1 shows the SSCP analysis of exons 9,13 , and 14 of five TIOD patients.

\section{Mutations identified in TPO gene}

We identified five different mutations, all of which were novel. Detected TPO mutant alleles included two missense and three frameshift mutations (Table 3). Partial nucleotide sequences of all the identified mutations are shown in Fig. 2. Mutation nomenclature follows the guidelines set by Antonarakis (1998). The lower case c in front of the nucleotide number stands for cDNA. To avoid confusion, a dot separates it from the nucleotide number.

Mutation distribution for each patient was described as follows.

Patient A This patient was characterized by SSCP as having aberrant shifts in exon 13 (lane 13, Fig. 1) and exon 14 (lane 6, Fig. 1). Direct sequencing identified a single T insertion between nucleotides 2268 and 2269 (c.22682269 ins T) (Fig. 2B) and a single $\mathrm{C}$ deletion at nucleotide 2413 (c.2413 delC) (Fig. 2C). The former introduces a stop codon immediately behind the insertion point, resulting in a truncated polypeptide of 756 amino acid 

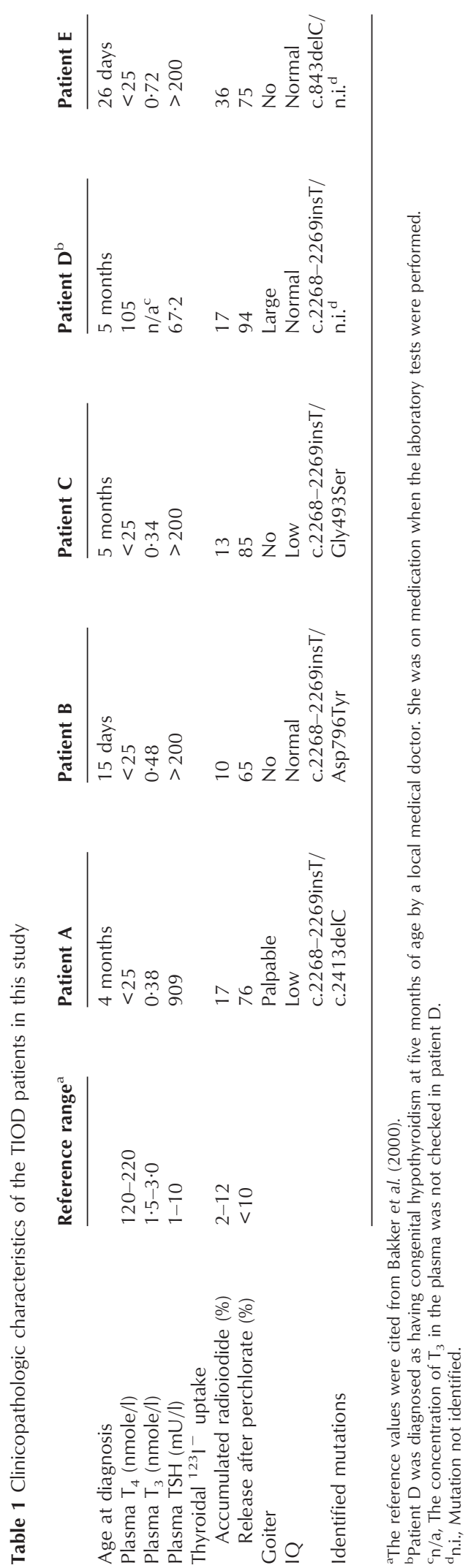
Table 2 PCR primers for mutation analysis of TPO gene

\begin{tabular}{|c|c|c|}
\hline & PCR primers & Fragment size $(b p)$ \\
\hline \multicolumn{3}{|l|}{ Exon } \\
\hline \multirow[t]{2}{*}{1} & 5'-ATCCAAGCGCAGAGTCAGTT-3' (1F) & 220 \\
\hline & 5'-CCCAAATTACAGCCACTCTT-3' (1R) & \\
\hline \multirow[t]{2}{*}{2} & 5'-ATGGCCTTGTCAGTGCTTG-3' (2F) & 224 \\
\hline & 5'-ССАТТАТGСССТСТАТТT-3' (2R) & \\
\hline \multirow[t]{2}{*}{3} & 5'-GGGCATCACCGCAGCAAG-3' (3F) & 228 \\
\hline & 5'-CCTGTCGGTGGCATTTGG-3' (3R) & \\
\hline \multirow[t]{2}{*}{4} & 5'-ACCAAAGATACCATAGACAA-3' (4F) & 296 \\
\hline & 5'-GCСССТGCACAAAGTCAAG-3' (4R) & \\
\hline \multirow[t]{2}{*}{5} & 5'-TCATGGTTTCCTATTTTTCA-3' (5F) & 202 \\
\hline & 5'-CAGATCCAACTTTCACGAGA-3' (5R) & \\
\hline \multirow[t]{2}{*}{6} & 5'-CCCCATCTCAAACACATCC-3' (6F) & 228 \\
\hline & 5'-CССТСССТСАGCATCACAG-3' (6R) & \\
\hline \multirow[t]{2}{*}{7} & $5^{\prime}$-TCATCTTTCTGCTACCAC-3' (7F) & 339 \\
\hline & 5'-ATACCATTCTGTTTGACG-3' (7R) & \\
\hline \multirow[t]{2}{*}{$8 \mathrm{~A}$} & 5'-GGCCCTGGGTGACCTTGAACTCC-3' (8AF) & 606 \\
\hline & 5'-CCССССGCTTTGCCCGCAGCCAC-3' (8AR) & \\
\hline \multirow[t]{2}{*}{$8 \mathrm{~B}$} & 5'-ACCCGCGGCAGCAGATGAA-3' (8BF) & 585 \\
\hline & 5'-CAGGGCGCCCAGCAGGACT-3' (8BR) & \\
\hline \multirow[t]{2}{*}{9} & 5'-GGGGCTGTCAAGGAAGATG-3' (9F)377 & 377 \\
\hline & 5'-CGCAGGGACCGCACTCACT-3' (9R) & \\
\hline \multirow[t]{2}{*}{10} & 5'-CTAGAACTGAGCCAAGAGC-3' (10F) & 245 \\
\hline & 5'-TGTGCAAGGGAAGGAACTG-3' (10R) & \\
\hline \multirow[t]{2}{*}{11} & 5'-TGAGATGGGCTGAACAAAA-3' (11F) & 323 \\
\hline & 5'-GACGCTCTGGATAGGAACG-3' (11R) & \\
\hline \multirow[t]{2}{*}{12} & 5'-TGGGCAGCTGGTCTTGAG-3' (12F) & 360 \\
\hline & 5'-CTCCTGGGGAAGATAAGC-3' (12R) & \\
\hline \multirow[t]{2}{*}{13} & 5'-TGTGGTTTTCTTTTCTCG-3' (13F) & 375 \\
\hline & 5'-AGCCCTTGCTTTCTATCC-3' (13R) & \\
\hline \multirow[t]{2}{*}{14} & 5'-GCAGCCGCTTCCTCTCACG-3' (14F) & 289 \\
\hline & 5'-CTCCGCCCTTCCCAATCAA-3' (14R) & \\
\hline \multirow[t]{2}{*}{15} & 5'-GACTCAGGCAGGACAACC-3' (15F) & 265 \\
\hline & 5'-TTCGGGAAAATAAAGCAG-3' (15R) & \\
\hline \multirow[t]{2}{*}{16} & 5'-GTCGCTCGTGCCGTGCTC-3' (16F) & 298 \\
\hline & 5'-AGGGAGCCCCAGCAGAGC-3' (16R) & \\
\hline \multirow[t]{3}{*}{17} & 5'-AATGTTTGTTCTGCATTTTTGC-3' (17F) & 382 \\
\hline & 5'-GACAGGAGGATTGCAAGAGTG-3' (17R) & \\
\hline & ACRS primers & \\
\hline \multirow[t]{2}{*}{13} & $\overline{5^{\prime} \text {-GATTCCAGCСТССССТCTGCAtA-3' (Nd13F) }}$ & 124 \\
\hline & 5'-AAGCACCTTTTGGCGAAGAAATT-3' (Nd13R) & \\
\hline
\end{tabular}

residues. The latter runs into a stop codon 26 residues later in the same exon. Direct sequencing of exon 13 and 14 of both parents' genomic DNA indicated that the patient inherited c.2268-2269 insT from the father and c.2413 delC from the mother (data not shown).

Patient B This patient was characterized by SSCP as having aberrant shifts in exon 13 (lane 12, Fig. 1). Direct sequencing of exon 13 indicated that he carried, in addition to c.2268-2269 ins T, a $G$ to $T$ transversion at nucleotide 2386 (Fig. 2E). c.2386 G>T would result in non-conservative replacement of acidic residue aspartic acid with aromatic tyrosine at amino acid position 796
(Asp796Tyr). The amplification-created restriction site method (ACRS) was used to identify the origin of the c. $2386 \mathrm{G}>\mathrm{T}$ allele in the parents and was also used to estimate its allele frequency in the general population to exclude the possibility of polymorphism. PCR product (124 bp) amplified with Nd13 primers (Table 2) created an $\mathrm{NdeI}$ (recognition sequences: $5^{\prime}-\mathrm{CATATG}-3^{\prime}$ ) restriction site for c.2386 G>T allele identification. NdeI digest of the PCR product amplified from the mutant allele will give two DNA fragments with sizes of $101 \mathrm{bp}$ and $23 \mathrm{bp}$ (the 23-bp fragment was too faint to be observed in the gel) respectively. The co-presence of 124-bp and 101-bp fragments in the propositus (lane 1, Fig. 3A) and his 


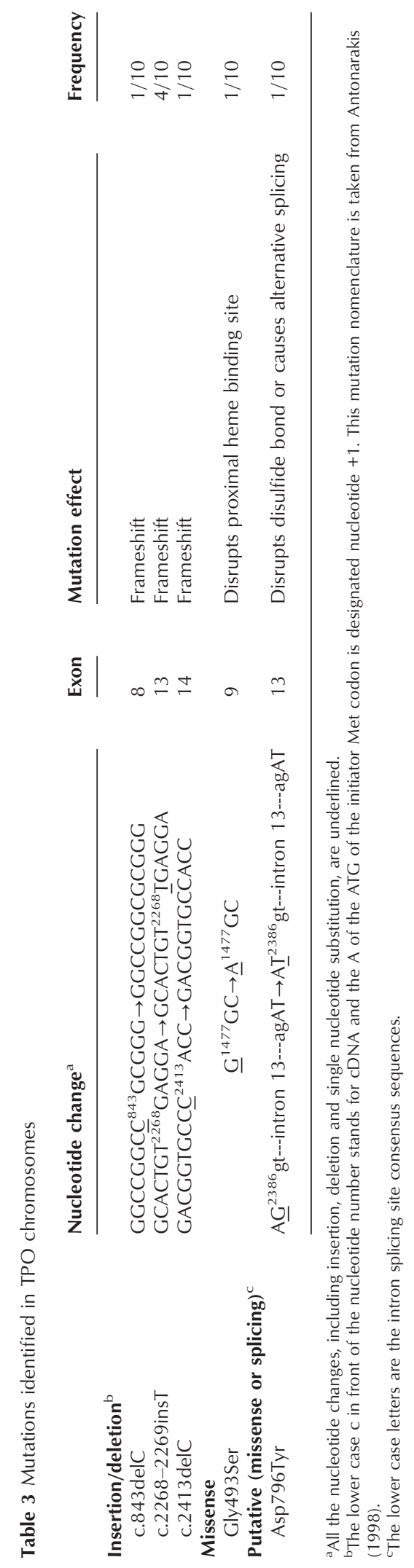




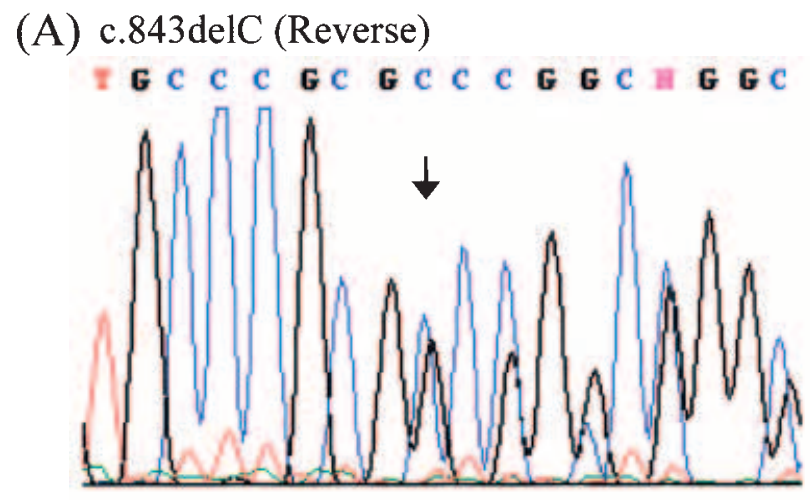

(B) c.2268-2269ins T (Forward)

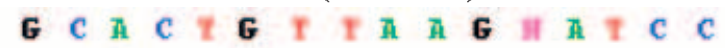

(C) c.2413delC (Forward)

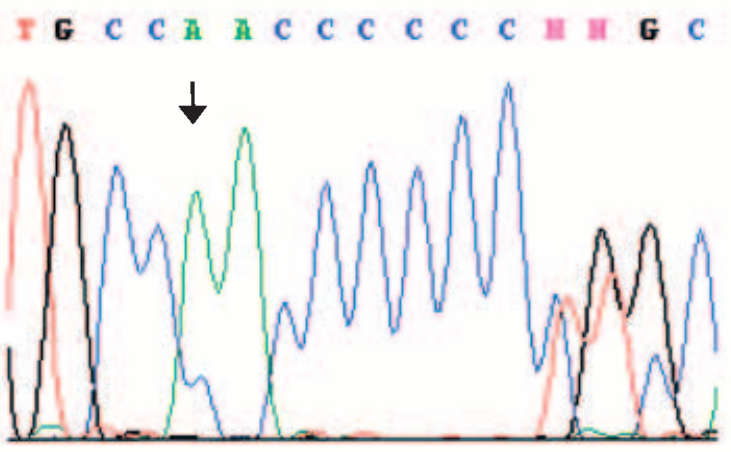

(D) Gly493Ser (Forward)
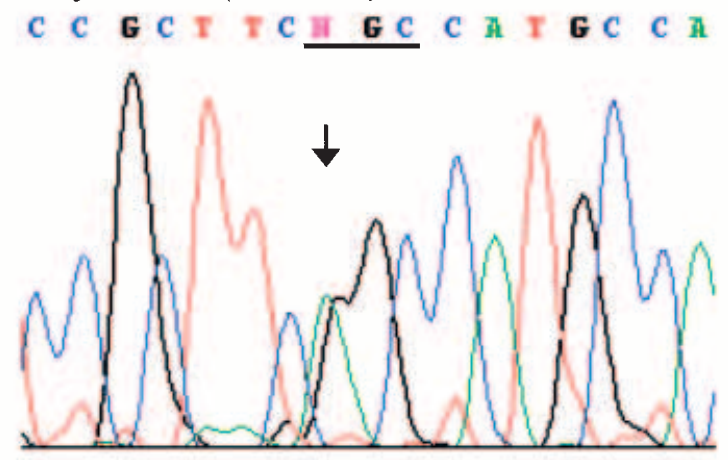

(E) Asp796Tyr (Reverse)

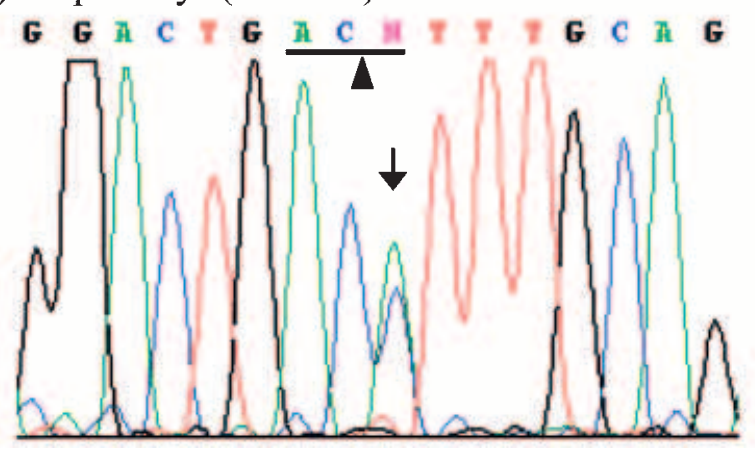

Figure 2 Electropherograms showing raw data for the identified novel mutations in the TPO gene. (A) Reverse nucleotide sequence demonstrates the deletion of a single $\mathrm{C}$ nucleotide. (B) Forward nucleotide sequence demonstrates the insertion of a single $\mathrm{T}$ nucleotide. (C) Forward nucleotide sequence demonstrates the deletion of a single $\mathrm{C}$ nucleotide. (D) Forward nucleotide sequence demonstrates a $G \rightarrow A$ transition, which results in an amino acid change of Gly493Ser (GGC $\rightarrow$ AGC). (E) Reverse nucleotide sequence demonstrates a $G \rightarrow T$ transversion, which results in an amino acid change of Asp796Tyr (GAT $\rightarrow$ TAT). Arrows indicate the positions of the nucleotide changes (deletion, insertion or single nucleotide substitution). Three nucleotides of the mutated codon are underlined. The solid triangle in (E) indicates the position of intron 13.

father (lane 2, Fig. 3A) indicated that he inherited c.2386 G>T from his father. Direct sequencing of both parents' genomic DNA further confirmed that the patient inherited the c.2386 G>T and c.2268-2269 ins T from his father and his mother respectively (data not shown). One hundred unrelated normal controls were screened by the aforementioned ACRS method and none was found to carry c.2386 G>T, thus excluding the possibility of polymorphism. The mutation effect of c. $2386 \mathrm{G}>\mathrm{T}$ will be discussed in a later section. 
A.

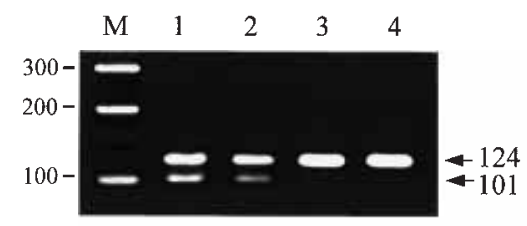

B.

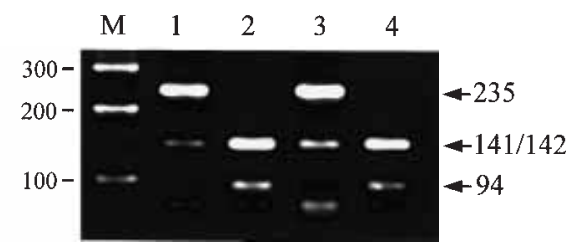

Figure 3 Allele segregation analysis of the families of patients $B$ and $C$ by the amplification-created restriction site (ACRS) and restriction fragment length polymorphism (RFLP) methods. (A) ACRS analysis of amplified exon 13 fragments by Ndel digest. Lane 1, patient B; lane 2, father; lane 3, mother; lane 4, normal control. (B) RFLP analysis of amplified exon 9 by Haell digest. Lane 1, patient C; lane 2, father; lane 3, mother; lane 4 normal control. A 100-bp ladder was used as a DNA size marker in lane $\mathrm{M}$.

Patient C This patient was characterized by SSCP as having aberrant shifts in exon 13 (lane 11, Fig. 1) and in exon 9 (lane 18, Fig. 1) respectively. Direct sequencing of exons 13 and 9 indicated that he carried c.2268-2269 insT in exon 13 and a $G$ to A transition (Fig. 2D) at nucleotide 1477 in exon 9. c.1477 G>A results in a non-conservative replacement of glycine residue with serine at amino acid position 493 (Gly493Ser). Since c.1477 G>A would disrupt a HaeIII restriction site (recognition sequences: $5^{\prime}-$ GGCC $-3^{\prime}$ ), the restriction fragment length polymorphism method (RFLP) was used to determine the allele segregation in the family and its allele frequency in the general population. A 377-bp PCR product was amplified with primer pairs of 9F and 9R (Table 2). HaeIII digest of PCR product amplified from normal control gave three fragments with sizes of $142 \mathrm{bp}, 141 \mathrm{bp}$, and $94 \mathrm{bp}$ respectively (lane 4, Fig. 3B). In the c.1477 G>A allele, HaeIII digest of PCR products gave two fragments with sizes of $235 \mathrm{bp}$ and $142 \mathrm{bp}$. As shown in the gel, the patient inherited the c.1477 G>A mutation from his mother (lane 1 and 3, Fig. 3B). Direct sequencing of exon 13 indicated that he inherited c.2268-2269 insT from his father (data not shown). HaeIII digest was used to screen 100 normal controls and none was found to carry c. $1477 \mathrm{G}>\mathrm{A}$, excluding the possibility of polymorphism. The detrimental effect of the c.1477 G>A mutation will be discussed in a later section.

Patient D This patient was found to have the same SSCP pattern (lane 10, Fig. 1) in exon 13 as the previous three patients. Direct sequencing confirmed that she carried a heterozygous c.2268-2269 insT mutation. Family study indicated that she inherited this mutation from her mother (data not shown). The other mutant allele was not found although all TPO coding exons and exon/intron boundaries were sequenced.

Patient E This patient was found, by direct sequencing, to carry a heterozygous mutation of c. 843 delC in exon 8 (Fig. 2A). This single nucleotide deletion would result in a frameshift in the polypeptide coding sequence, which would run into a termination signal after 35 residues in the same exon. The other mutant allele was not found although all TPO coding exons and exon/intron boundaries were sequenced.

\section{Deleterious effect of identified missense mutations}

Three out of five mutations identified in this study would cause frameshift in TPO polypeptide coding sequences, resulting in a truncated polypeptide. The deleterious effect of these mutations is obvious. The detrimental effect caused by the other two missense mutations was not so significant. To evaluate the effect of these two mutations, the amino acid sequences neighboring the mutations were compared with those of various peroxidases. Gly493 is located next to His 494 . Through $3 \AA ̊$ X-ray crystallography of canine myeloperoxidase, Zeng and Fenna (1992) showed that His336 of canine myeloperoxidase (MPO) acted as a proximal histidine, one of the binding ligands to the iron center of the heme prosthetic group. Its corresponding amino acid in human TPO (Kimura et al. 1989) is His494. As shown in Fig. 4A, Ala489, Phe490, Arg491, Gly493, and His494 are well conserved among all known TPO polypeptides, including pig (Magnusson et al. 1987b), mouse (Kotani et al. 1993), and rat (Derwahl et al. 1989), and also in human (Morishita et al. 1987) and mouse myeloperoxidases (Venturelli et al. 1989), human eosinophil peroxidase (Ten et al. 1989), and human and bovine lactoperoxidases (Dull et al. 1990). Phe492, although not conserved among all peroxidases, is conservatively substituted with tyrosine residue in human and mouse myeloperoxidase. Substitution of Gly493 with a bulkier serine residue next to the crucial proximal histidine (His494) would interfere with the binding of the heme prosthetic group and/or influence the electron transfer. Also shown in Fig. 4B are Asp796 and its neighboring residues, from Pro791 to Cys800, which are either well reserved or relatively conservative (Leu793 and Val797) among various thyroid peroxidases, including pig, mouse and rat. Earlier study of human thyroid peroxidase indicated that the amino acids from Asp796 to Val839 
A.

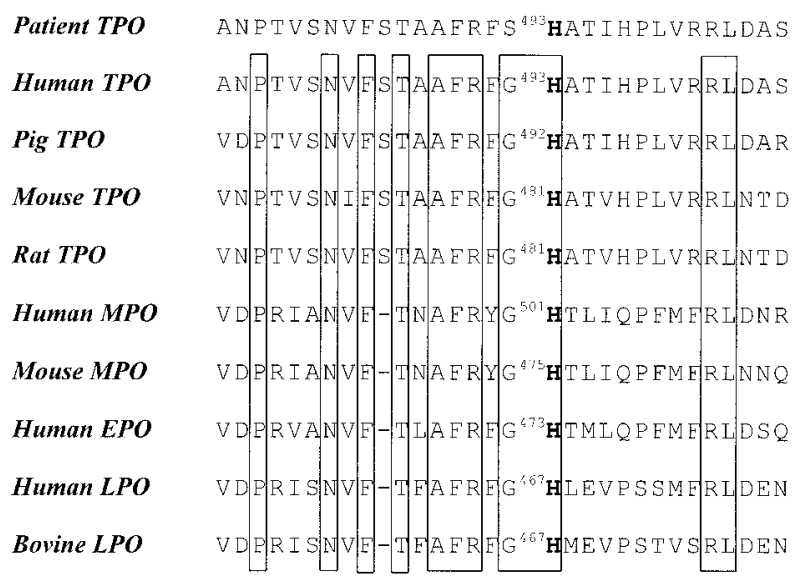

B.

Patient TPO

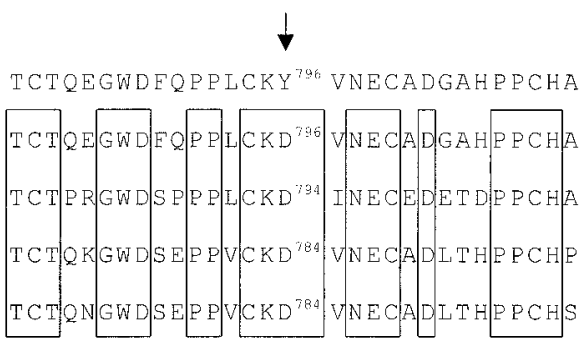

Rat TPO

Figure 4 Comparison of the amino acid sequences neighboring the missense mutations in (A) exon 9 and (B) exon 13 of the TPO gene among various peroxidases. Arrows mark the missense mutations. His494, one of the binding ligands to the iron center of the heme prosthetic group is bold-faced (A). Conserved amino acids are boxed. The numbering of amino acid sequences is adopted from the following references: human TPO, Kimura et al. (1987); pig TPO, Magnusson et al. (1987b); mouse TPO, Kotani et al. (1993); rat TPO, Derwahl et al. (1989); human MPO, Morishita et al. (1987); mouse MPO, Venturelli et al. (1989); human eosinophil peroxidase (EPO), Ten et al. (1989); human and bovine lactoperoxidase (LPO), Dull et al. (1990).

acted as an epidermal growth factor (EGF)-like potential calcium-binding domain, where there are three disulfide bonds $\left(C^{800}-C^{814}, C^{808}-C^{823}\right.$, and $\left.C^{825}-C^{838}\right)$ formed. Substitution of Asp796Tyr would interfere with the disulfide bond linkage and/or disrupt the tertiary structure of EGF-like calcium-binding domain. There is also another possibility. Since nucleotide G2386 is located at the exon 13/intron 13 boundary (Table 3 ), the nucleotide change of c.2386 G>T would cause alternative splicing of the TPO gene. Unfortunately, thyroid tissues from patient $\mathrm{B}$ were not available to differentiate these two hypotheses.

\section{Discussion}

This is the first systematic mutation analysis ever performed in Taiwan Chinese with total iodide organification defect (TIOD). Mutation analysis of the TPO gene in TIOD patients had been reported in various ethnic populations, including Dutch (Bikker et al. 1995, Bakker et al. 2000), Amish (Pannain et al. 1999), Brazilians (Santos et al. 1999), Germans (Gruters et al. 1996), and Japanese (Kotani et al. 1999). All these except Japanese are of Caucasian descent. It is interesting to note that one of the TPO mutant alleles identified in Japanese TIOD was reported previously in Dutch patients. However, none of the TPO mutations identified in the Taiwan Chinese TIOD patients had previously been identified in other ethnic peoples, demonstrating the heterogeneic nature of TPO mutation among different ethnic groups. The GGCC duplication at nucleotide 1277 in exon 8, reported to be most prevalent $(36 \%)$ among the Dutch, was not found in our TIOD patients. We did identify a single nucleotide insertion mutation (c.2268-2269 insT) that was prevalent among our TIOD patients. This TPO mutant allele was detected in four out of five patients in compound heterozygous fashion, accounting for $40 \%$ of the total mutant TPO alleles investigated. Despite rigorous screening of TPO's coding exons and their exon/intron boundaries, we could detect only one mutant allele in two patients. It is unlikely that the TIOD of these two patients was caused by another gene defect because the identified mutant alleles were both frameshift mutations. The undetected mutations might fall either in the promoter/ terminator region or within the intron region, creating a new splicing site. It is also possible that the mutation might be a large deletion in the TPO gene, which would not be identified through SSCP screening and direct sequencing. More work will be needed to identify the undetected TPO mutant alleles in the future.

\section{Acknowledgement}

This work was supported by a grant from National Science Council (NSC 89-2314-B-039-029-), Taiwan, Republic of China.

\section{References}

Abramowicz MJ, Targovnik HM, Varela V, Cochaux P, Krawiec L, Pisarev MA, Propato FV, Juvenal G, Chester HA \& Vassart G 1992 Identification of a mutation in the coding sequence of the human thyroid peroxidase gene causing congenital goiter. Journal of Clinical Investigation 90 1200-1204.

Antonarakis SE 1998 Recommendations for a nomenclature system for human gene mutations. Nomenclature Working Group. Human Mutation 11 1-3.

Bakker B, Bikker H, Vulsma T, de Randamie JS, Wiedijk BM \& de Vijlder JJ 2000 Two decades of screening for congenital hypothyroidism in The Netherlands: TPO gene mutations in total iodide organification defects (an update). Journal of Clinical Endocrinology and Metabolism 85 3708-3712.

Bikker H, den Hartog MT, Baas F, Gons MH, Vulsma T \& de Vijlder JJ 1994 A 20-basepair duplication in the human thyroid 
peroxidase gene results in a total iodide organification defect and congenital hypothyroidism. Journal of Clinical Endocrinology and Metabolism 79 248-252.

Bikker H, Vulsma T, Baas F \& de Vijlder JJ 1995 Identification of five novel inactivating mutations in the human thyroid peroxidase gene by denaturing gradient gel electrophoresis. Human Mutation 6 9-16.

Bikker H, Baas F \& de Vijlder JJ 1997 Molecular analysis of mutated thyroid peroxidase detected in patients with total iodide organification defects. Journal of Clinical Endocrinology and Metabolism 82 649-653.

Dai G, Levy O \& Carrasco N 1996 Cloning and characterization of the thyroid iodide transporter. Nature 379 458-460.

Derwahl M, Seto P \& Rapoport B 1989 Complete nucleotide sequence of the cDNA for thyroid peroxidase in FRTL5 rat thyroid cells. Nucleic Acids Research 178380.

Dull TJ, Uyeda C, Strosberg AD, Nedwin G \& Seilhamer JJ 1990 Molecular cloning of cDNAs encoding bovine and human lactoperoxidase. DNA and Cell Biology 9 499-509.

Endo Y, Onogi S, Umeki K, Yamamoto I, Kotani T, Ohtaki S \& Fujita T 1995 Regional localization of the gene for thyroid peroxidase to human chromosome 2 p25 and mouse chromosome 12C. Genomics 25 760-761.

Gruters A, Kohler B, Wolf A, Soling A, de Vijlder L, Krude H \& Biebermann H 1996 Screening for mutations of the human thyroid peroxidase gene in patients with congenital hypothyroidism. Experimental and Clinical Endocrinology and Diabetes 104 (Suppl 4) $121-123$.

Kimura S, Kotani T, McBride OW, Umeki K, Hirai K, Nakayama T \& Ohtaki S 1987 Human thyroid peroxidase: complete cDNA and protein sequence, chromosome mapping, and identification of two alternately spliced mRNAs. PNAS 84 5555-5559.

Kimura S., Hong YS, Kotani T, Ohtaki S \& Kikkawa F 1989 Structure of the human thyroid peroxidase gene: comparison and relationship to the human myeloperoxidase gene. Biochemistry 28 $4481-4489$.

Kotani T, Umeki K, Yamamoto I, Takeuchi M, Takechi S, Nakayama T \& Ohtaki S 1993 Nucleotide sequence of the cDNA encoding mouse thyroid peroxidase. Gene 123 289-290.

Kotani T, Umeki K, Yamamoto I, Maesaka H, Tachibana K \& Ohtaki S 1999 A novel mutation in the human thyroid peroxidase gene resulting in a total iodide organification defect. Journal of Endocrinology 160 267-273.

Libert F, Ruel J, Ludgate M, Swillens S, Alexander N, Vassart G \& Dinsart C 1987 Complete nucleotide sequence of the human thyroperoxidase-microsomal antigen cDNA. Nucleic Acids Research 156735 .
Magnusson RP, Chazenbalk GD, Gestautas J, Seto P, Filetti S, DeGroot LJ \& Rapoport B 1987a Molecular cloning of the complementary deoxyribonucleic acid for human thyroid peroxidase. Molecular Endocrinology 1 856-861.

Magnusson RP, Gestautas J, Taurog A \& Rapoport B 1987 b Molecular cloning of the structural gene for porcine thyroid peroxidase. Journal of Biological Chemistry 262 13885-13888.

Morishita K, Kubota N, Asano S, Kaziro Y \& Nagata S 1987 Molecular cloning and characterization of cDNA for human myeloperoxidase. Journal of Biological Chemistry 262 3844-3851.

Pannain S, Weiss RE, Jackson CE, Dian D, Beck JC, Sheffield VC, Cox N \& Refetoff S 1999 Two different mutations in the thyroid peroxidase gene of a large inbred Amish kindred: power and limits of homozygosity mapping. Journal of Clinical Endocrinology and Metabolism 84 1061-1071.

Pohlenz J, Rosenthal IM, Weiss RE, Jhiang SM, Burant C \& Refetoff S 1998 Congenital hypothyroidism due to mutations in the sodium/iodide symporter: identification of a nonsense mutation producing a downstream cryptic $3^{\prime}$ splice site. Journal of Clinical Investigation 101 1028-1035.

Santos CL, Bikker H, Rego KG, Nascimento AC, Tambascia M, de Vijlder JJ \& Medeiros-Neto G 1999 A novel mutation in the TPO gene in goitrous hypothyroid patients with iodide organification defect. Clinical Endocrinology 51 165-172.

Taurog A 1996 Hormone synthesis: thyroid iodine metabolism. In Werner's The Thyroid, pp 53-97. Eds S Ingbar \& L Braverman. Philadelphia: Lippincott.

Ten RM, Pease LR, McKean DJ, Bell MP \& Gleich GJ 1989 Molecular cloning of the human eosinophil peroxidase. Evidence for the existence of a peroxidase multigene family. Journal of Experimental Medicine 169 1757-1769.

Vassart G, Dumont JE \& Refetoff S 1995 Thyroid disorders. In The Metabolic and Molecular Basis of Inherited Disease, pp 2883-2928. Eds CR Scriver, AL Beaudet, WS Sly \& D Valle. New York: McGraw-Hill.

Venturelli D, Shirsat N, Gemperlein I, Bittenbender S, Hudson S \& Rovera G 1989 Nucleotide sequence of cDNA for murine myeloperoxidase. Nucleic Acids Research 175852.

Zeng J \& Fenna RE 1992 X-ray crystal structure of canine myeloperoxidase at 3 A resolution. Journal of Molecular Biology 226 185-207.

Received 5 October 2001 Accepted 30 October 2001 